The Conflicting Role of Water in the Activation of

$\mathrm{H}_{2} \mathrm{O}_{2}$ and the Formation and Reactivity of non-

Heme $\mathrm{Fe}^{\mathrm{III}}-\mathrm{OOH}$ and $\mathrm{Fe}^{\mathrm{III}}-\mathrm{O}-\mathrm{Fe}^{\mathrm{III}}$ Complexes at

\title{
Room Temperature
}

Sandeep K. Padamati, Apparao Draksharapu, Duenpen Unjaroen, Wesley R. Browne*

Supporting Information 


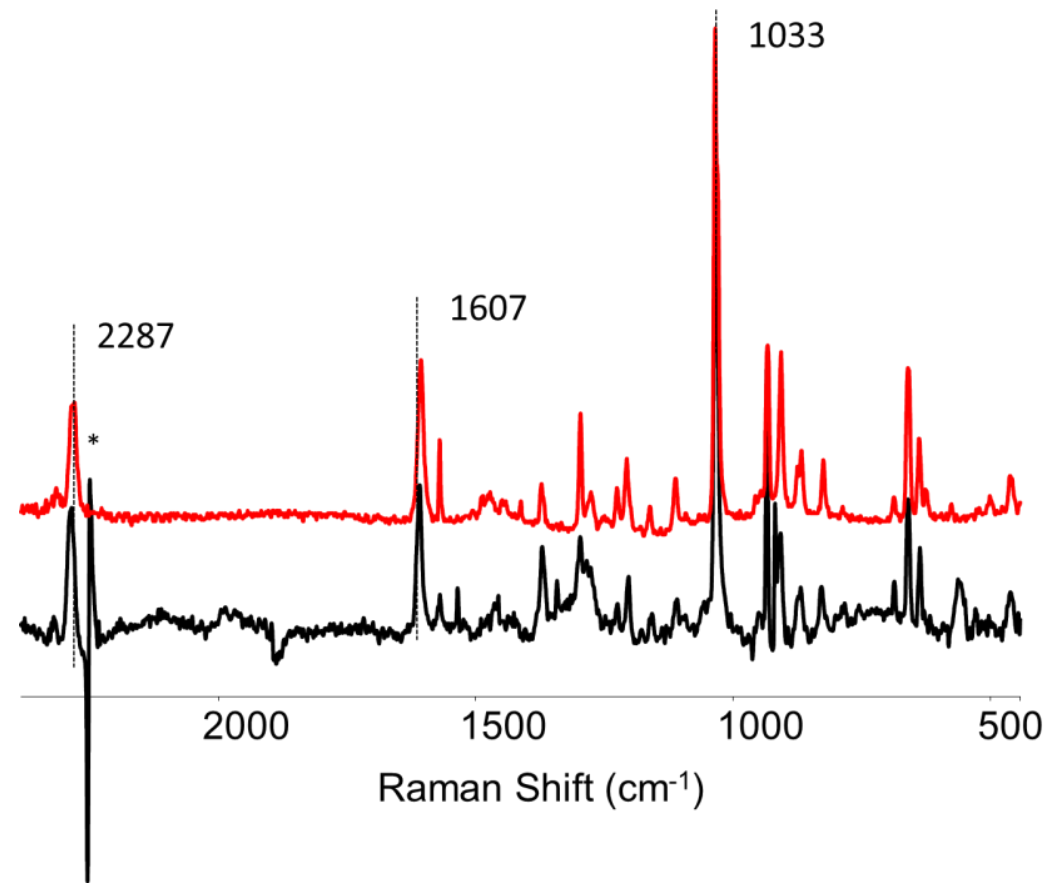

Figure S 1, Raman spectra of $\mathbf{1}$ in solid (red) and in $\mathrm{CH}_{3} \mathrm{CN}$ (black). Spectra were recorded at $\lambda_{\text {exc }} 785 \mathrm{~nm} . *$ Artifact from solvent subtraction. 
(a)

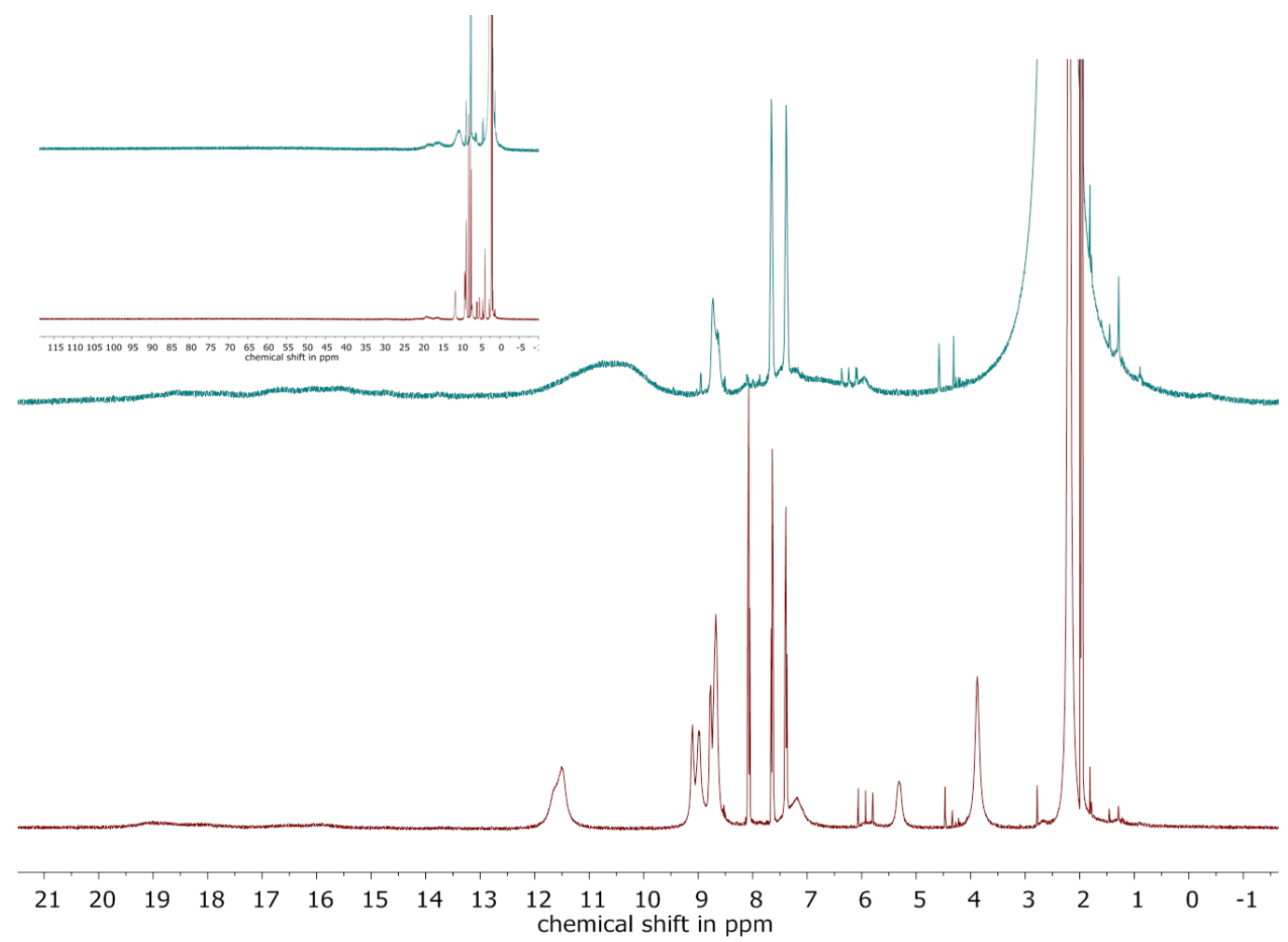

(b)

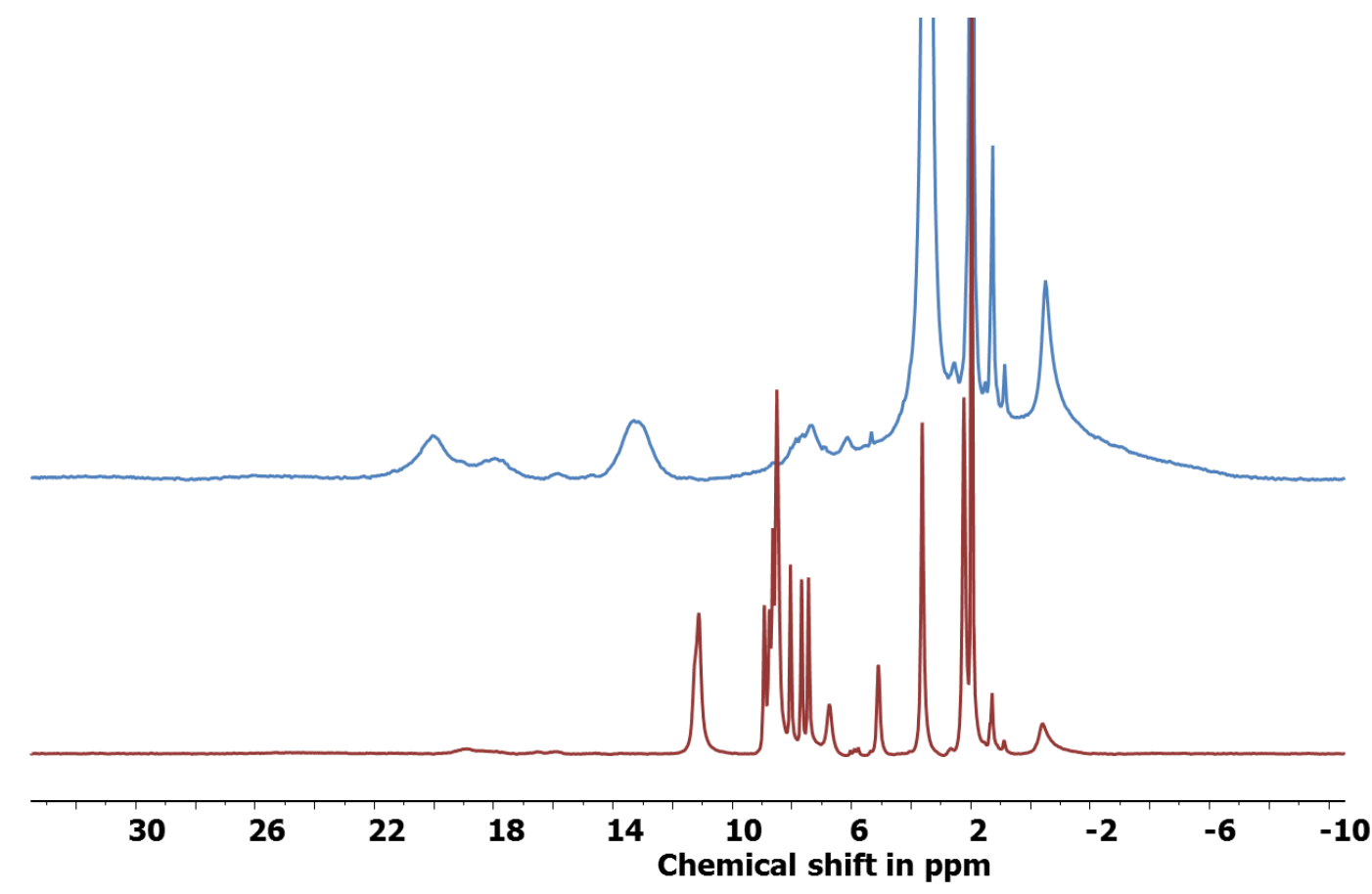

Figure S 2. ${ }^{1} \mathrm{H}$ NMR $400 \mathrm{MHz}$ spectra of 1 ((a) $1 \mathrm{mM}$ and (b) $10 \mathrm{mM}$ ) in $\mathrm{CD}_{3} \mathrm{CN}$ (brown) and after addition of water $(1 \mathrm{M}$, blue $)$ at $400 \mathrm{MHz}$. 


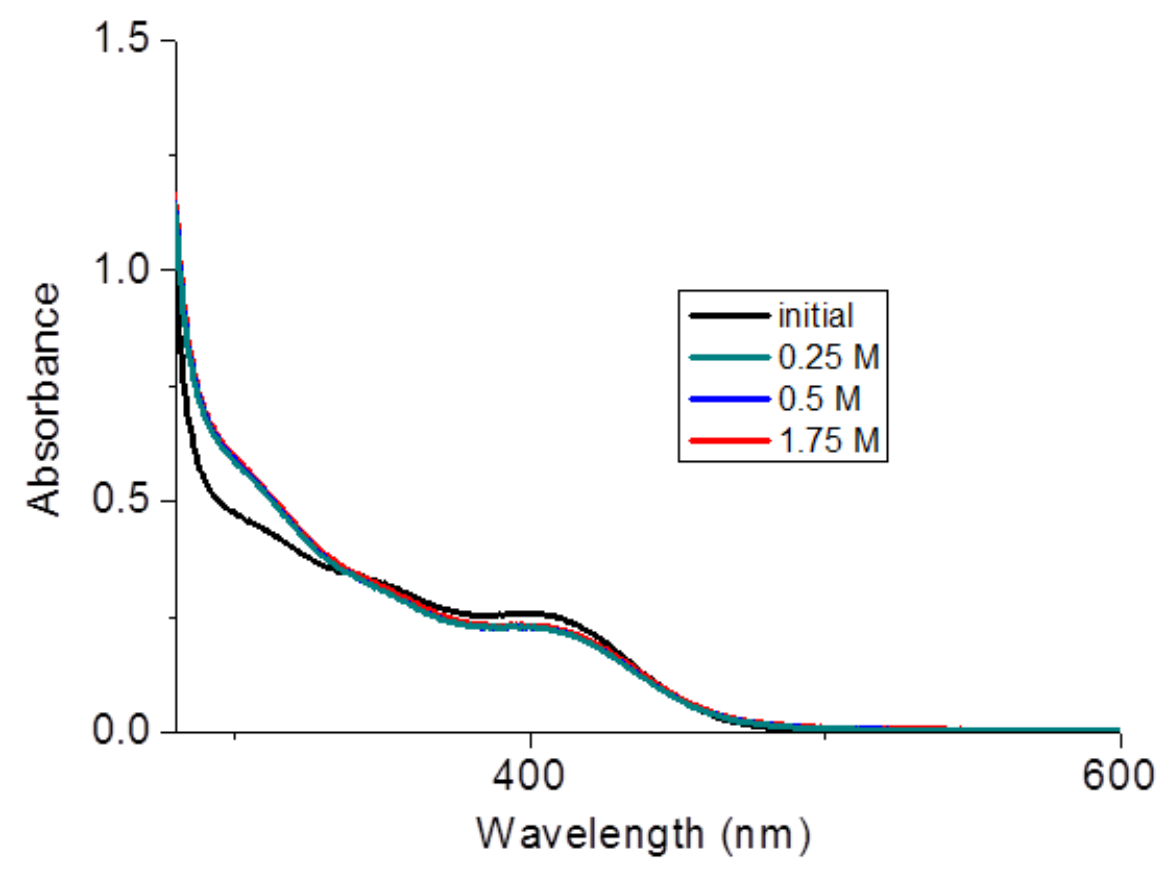

Figure S 3. UV/vis absorption spectrum of $1(0.25 \mathrm{mM})$ in water (black) and with 0.25 (green), 0.5 (blue) and 1.75 (red) M acetonitrile added.

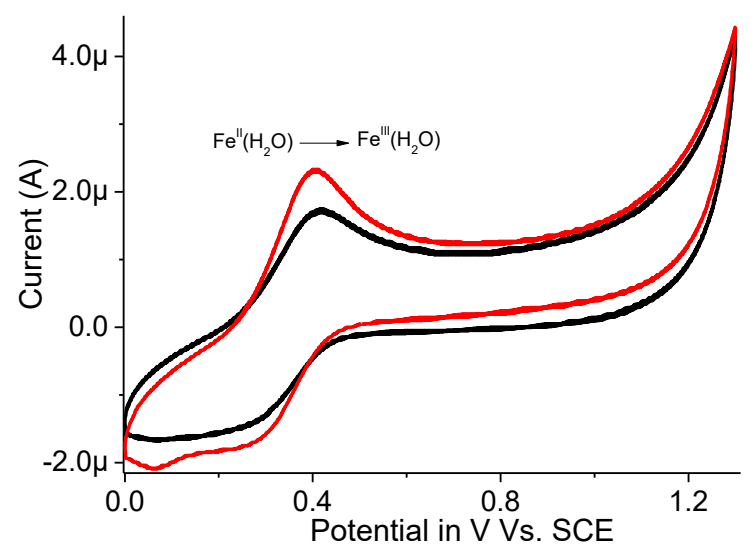

Figure S 4. Cyclic voltammetry of $1(0.25 \mathrm{mM})$ in water $\left(0.03 \mathrm{M} \mathrm{KNO}_{3}\right)$ (red) and after addition of acetonitrile (1.25 M, black). 


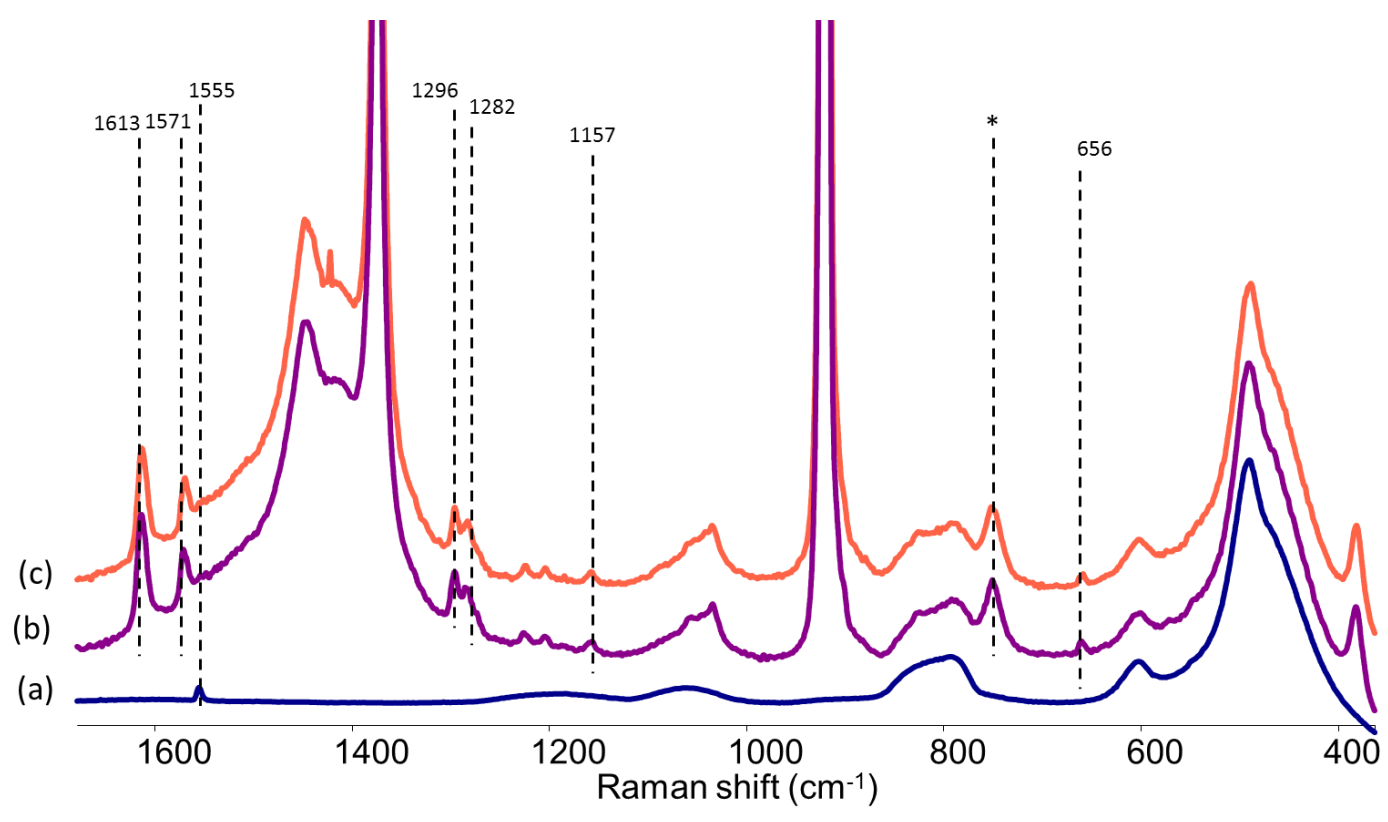

Figure S 5. Resonance Raman spectra of (a) quartz (blue), (b) 1 in acetonitrile (0.25 mM, purple) and with water $\left(1.25 \mathrm{M}\right.$, red). Spectra were recorded at $\lambda_{\text {exc }} 355 \mathrm{~nm} .{ }^{*}$ normalized to the acetonitrile band at $750 \mathrm{~cm}^{-1}$.

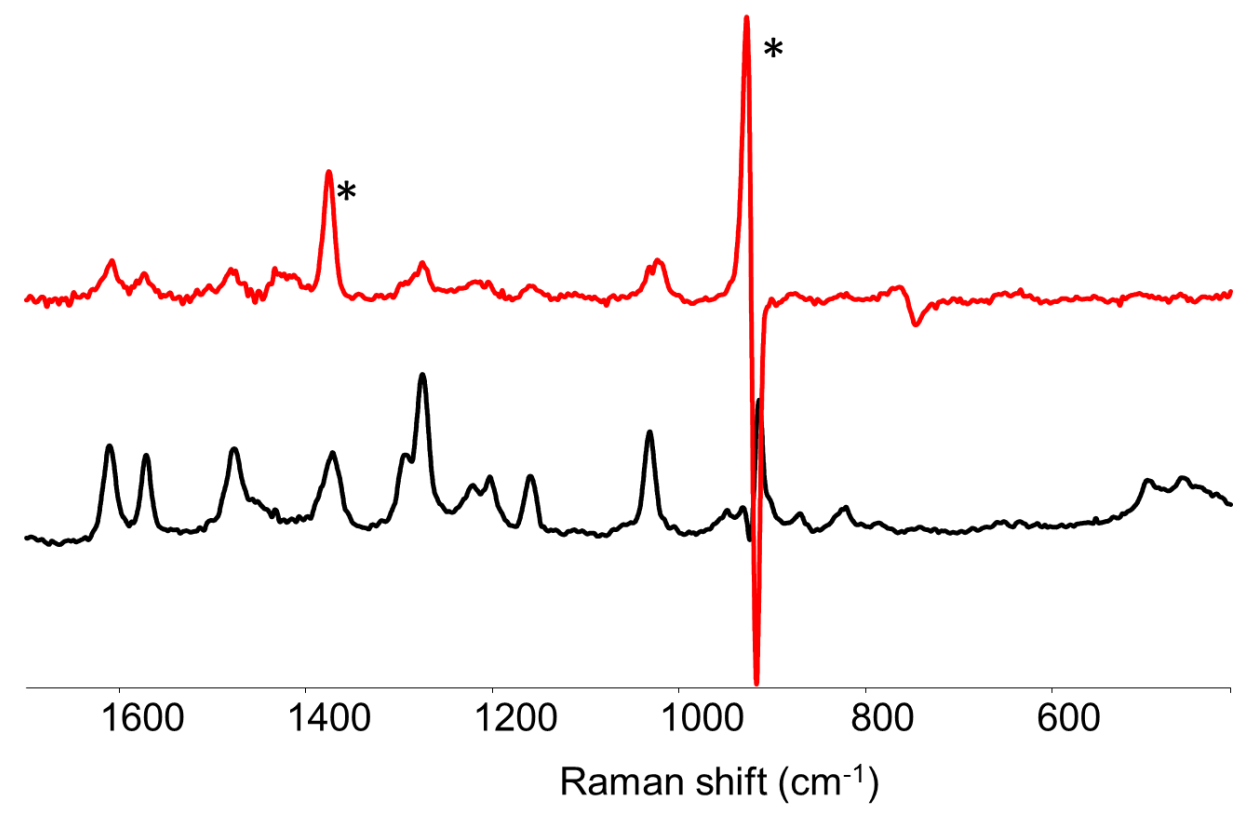

Figure S 6. Resonance Raman spectra of 1 in acetonitrile $(0.25 \mathrm{mM}$, black) and with water (1.25 M, red). Spectra were recorded at $\lambda_{\mathrm{exc}} 457 \mathrm{~nm} .{ }^{*}$ artefact due to imperfect solvent subtraction 

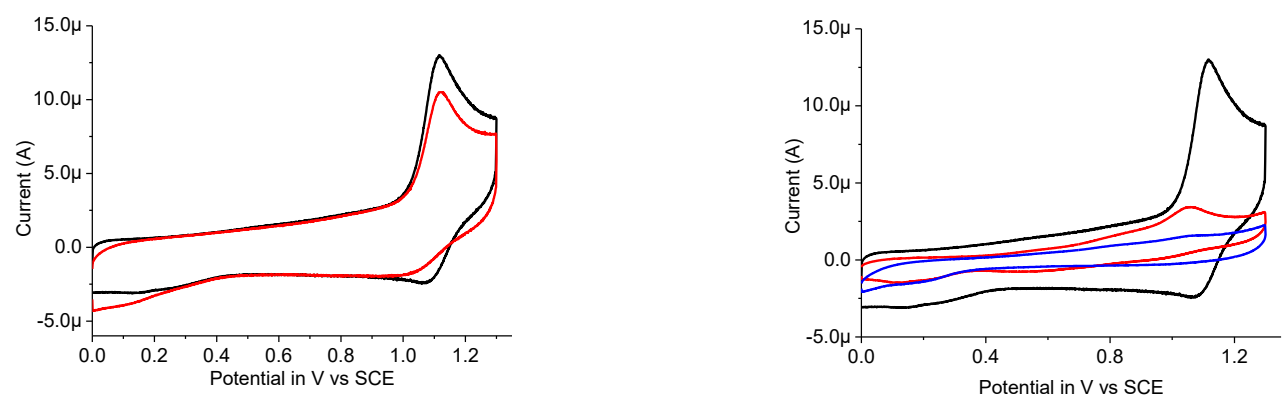

Figure S 7. Cyclic voltammetry of 1 in acetonitrile $\left(0.25 \mathrm{mM}, 0.5 \mathrm{~V} \mathrm{~s}^{-1}, 0.1 \mathrm{M} \mathrm{TBAPF}_{6}\right)$ (a) before (black) and after addition of 1 equiv. $\mathrm{H}_{2} \mathrm{O}_{2}$ (red), and (b) before (black) and after addition of $\mathrm{H}_{2} \mathrm{O}\left(0.5 \mathrm{M}\right.$, red) and subsequent addition of 1 equiv. $\mathrm{H}_{2} \mathrm{O}_{2}$ (blue).
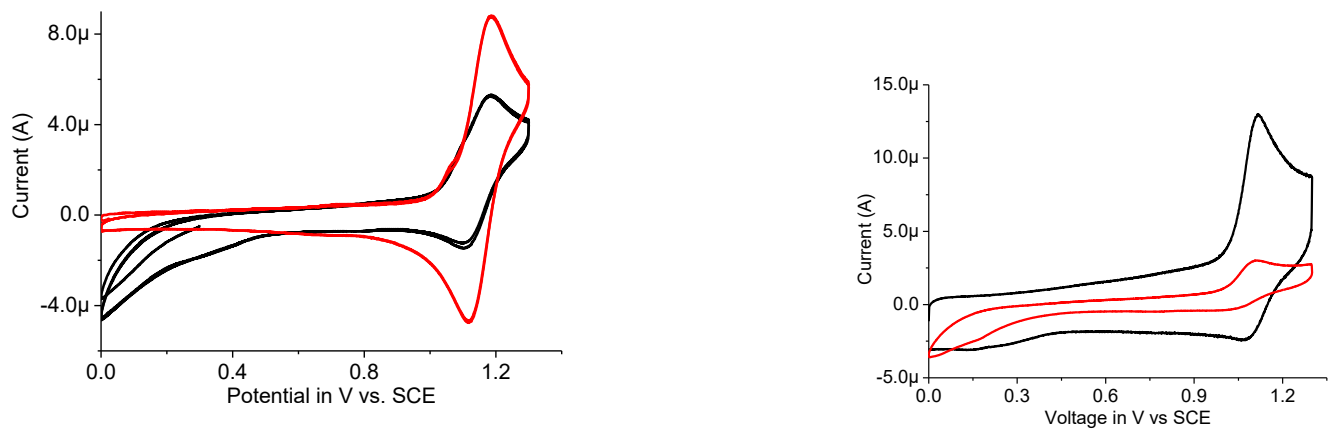

Figure S 8. Cyclic voltammograms of 1 in acetonitrile (left: $0.5 \mathrm{mM}$ at $0.1 \mathrm{~V} \mathrm{~s}^{-1}$, and right: $0.25 \mathrm{mM}, 0.5 \mathrm{~V} \mathrm{~s}^{-1}$ ), $0.1 \mathrm{M} \mathrm{TBAPF}_{6}$ ) (red) and after addition of 10 and 25 equiv. $\mathrm{H}_{2} \mathrm{O}_{2}$ (black), respectively. 

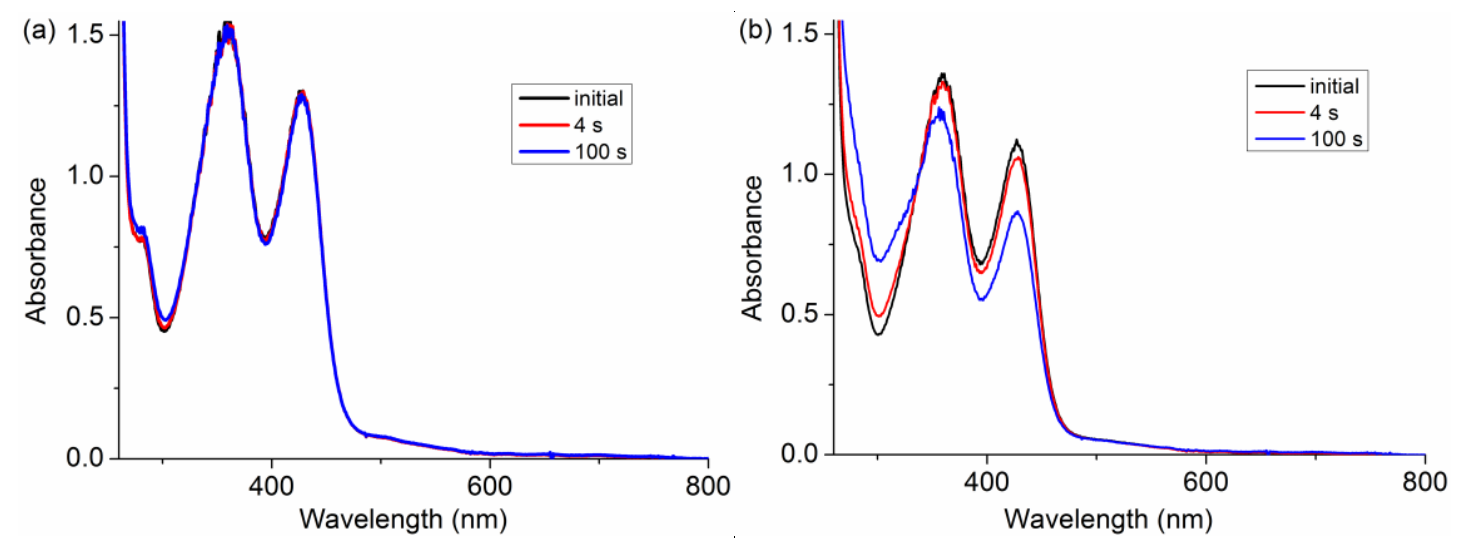

Figure S 9. UV/vis absorption at $278 \mathrm{~K}$ of $\mathbf{1}(0.25 \mathrm{mM})$ (a) in acetonitrile and (b) in acetonitrile with water $(1.25 \mathrm{M}$, black) before (black) and $4 \mathrm{~s}$ (red) and $100 \mathrm{~s}$ (blue) after addition of 1 equiv. of $\mathrm{H}_{2} \mathrm{O}_{2}$.
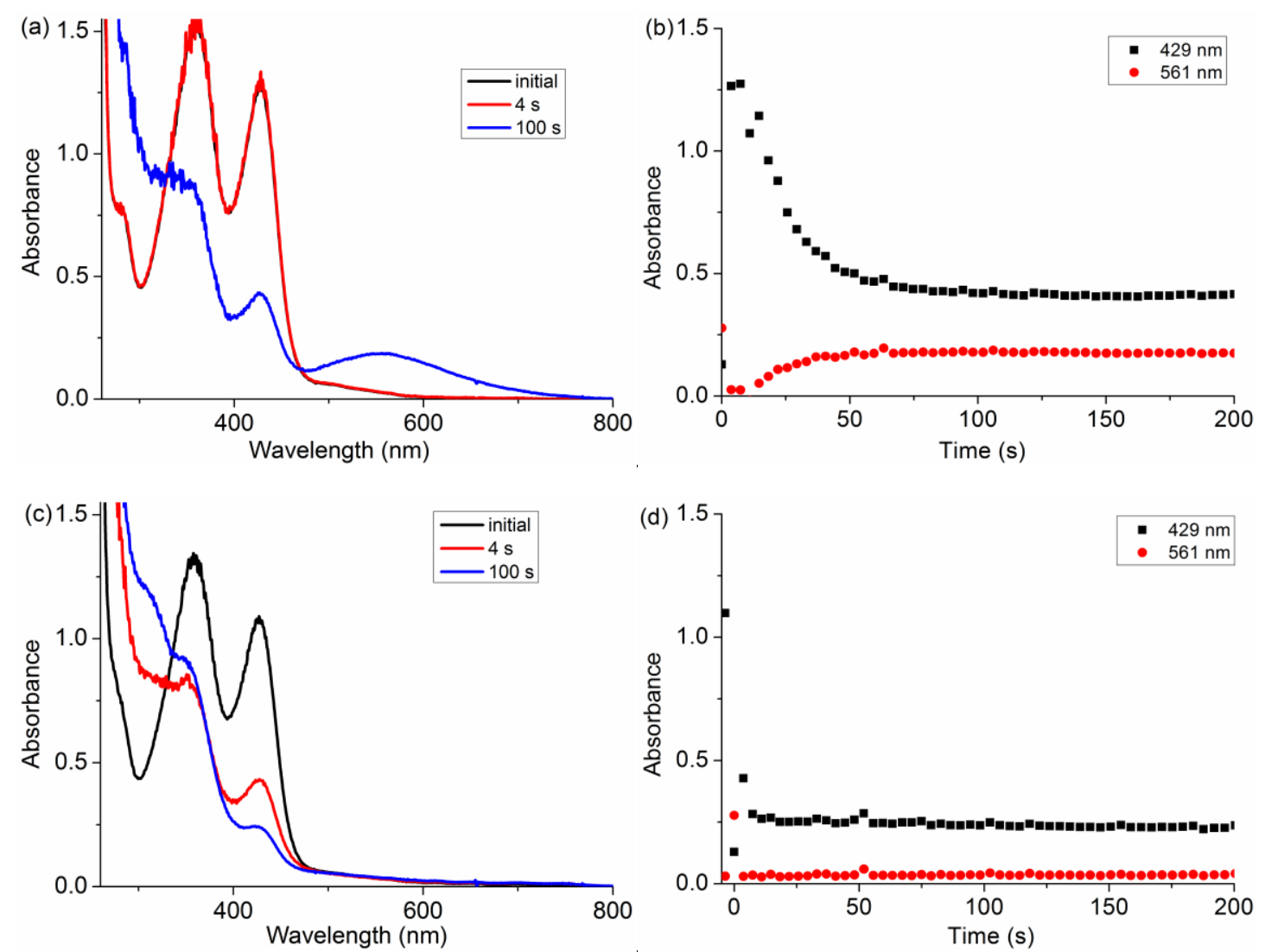

Figure S 10. (a) UV/Vis absorption spectrum of $\mathbf{1}(0.25 \mathrm{mM})$ in acetonitrile at $278 \mathrm{~K}$, and (c) in acetonitrile with water (1.25 M) at $278 \mathrm{~K}$ before (black), immediately after (red), and $100 \mathrm{~s}$ after (blue) addition of 100 equiv. of $\mathrm{H}_{2} \mathrm{O}_{2}$ \{corresponding time dependence of absorbance at $429 \mathrm{~nm}$ (black) and $561 \mathrm{~nm}$ (red) shown as (b) and (d), respectively\}. 


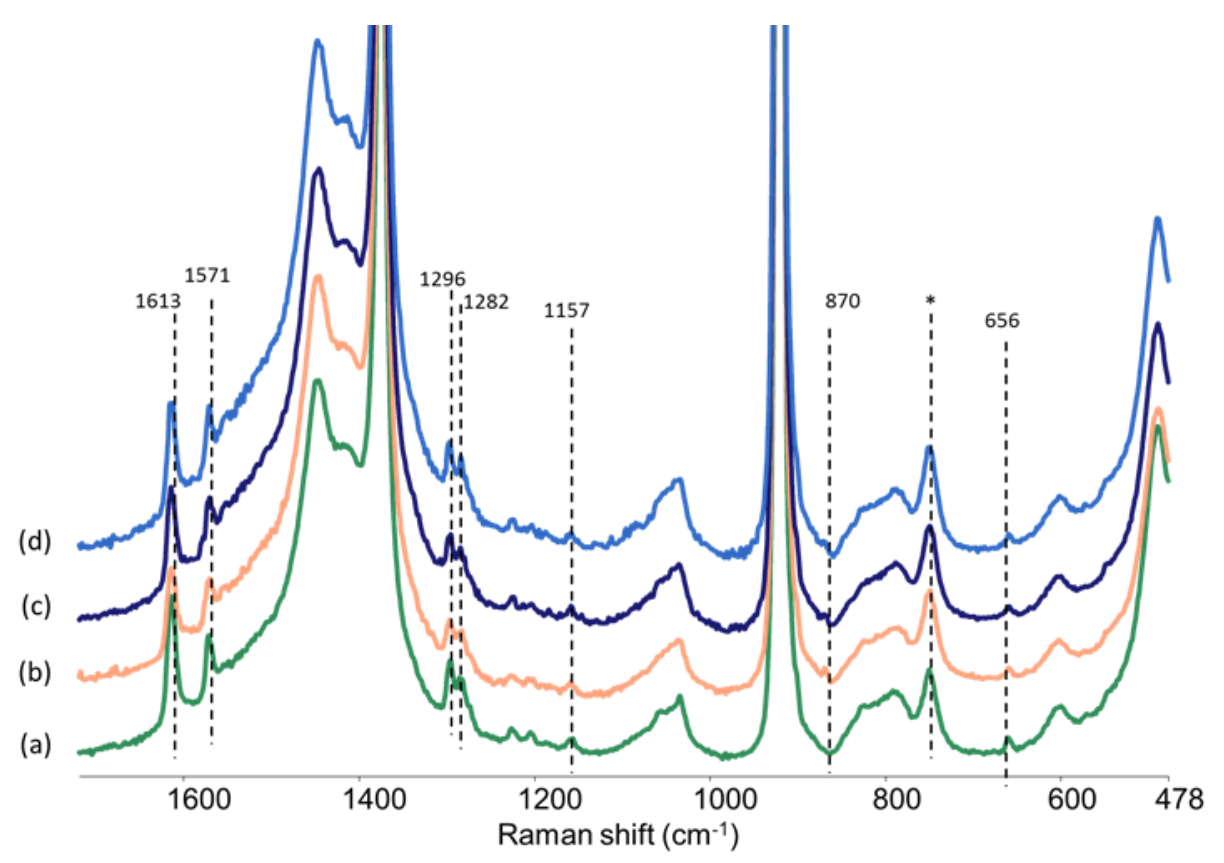

Figure S 11. Resonance Raman spectra at $\lambda_{\text {exc }} 355 \mathrm{~nm}$ of $1(0.25 \mathrm{mM})$ acetonitrile before (a) and $40 \mathrm{~s}(\mathrm{~b}), 100 \mathrm{~s}(\mathrm{c})$, and $160 \mathrm{~s}(\mathrm{~d})$ after addition of 100 equiv. of $\mathrm{H}_{2} \mathrm{O}_{2}$.

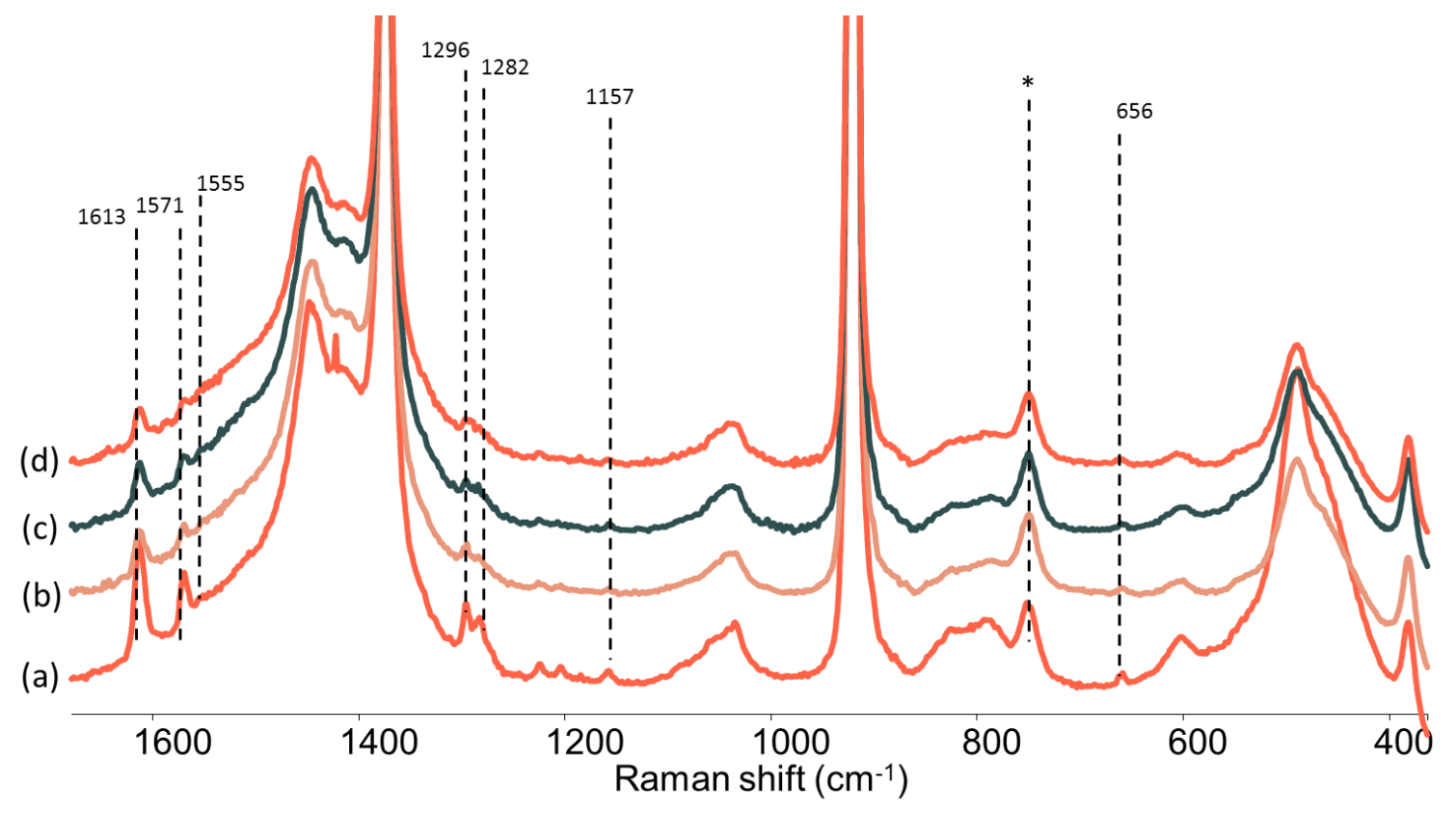

Figure S 12. Resonance Raman spectra at $\lambda_{\text {exc }} 355 \mathrm{~nm} 1(0.25 \mathrm{mM})$ in acetonitrile with water $(1.25 \mathrm{M})$ before (a) and $40 \mathrm{~s}(\mathrm{~b}), 100 \mathrm{~s}(\mathrm{c})$, and $140 \mathrm{~s}(\mathrm{~d})$ after addition of 100 equiv. of $\mathrm{H}_{2} \mathrm{O}_{2}$. 

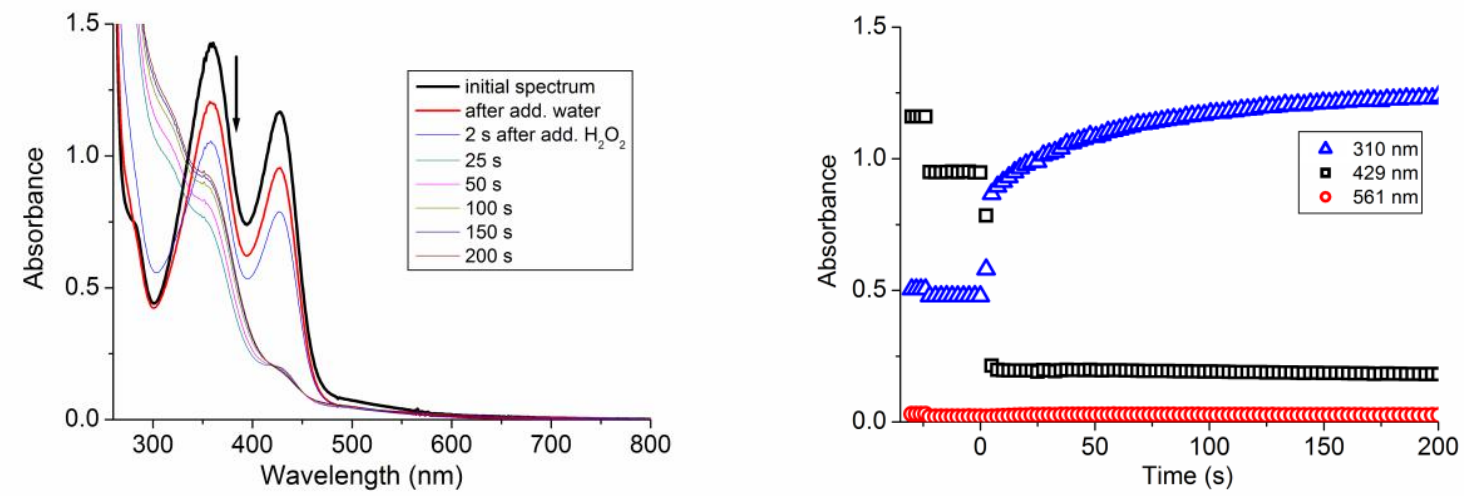

Figure S 13. (left) UV/Vis absorption spectrum of $1(0.25 \mathrm{mM})$ in acetonitrile with water $(1.25 \mathrm{M})$ and after subsequent addition of 100 equiv. of $\mathrm{H}_{2} \mathrm{O}_{2}$, and (right) corresponding time dependence of absorbance at $310 \mathrm{~nm}$ (blue), $429 \mathrm{~nm}$ (black) and $561 \mathrm{~nm}$ (red).
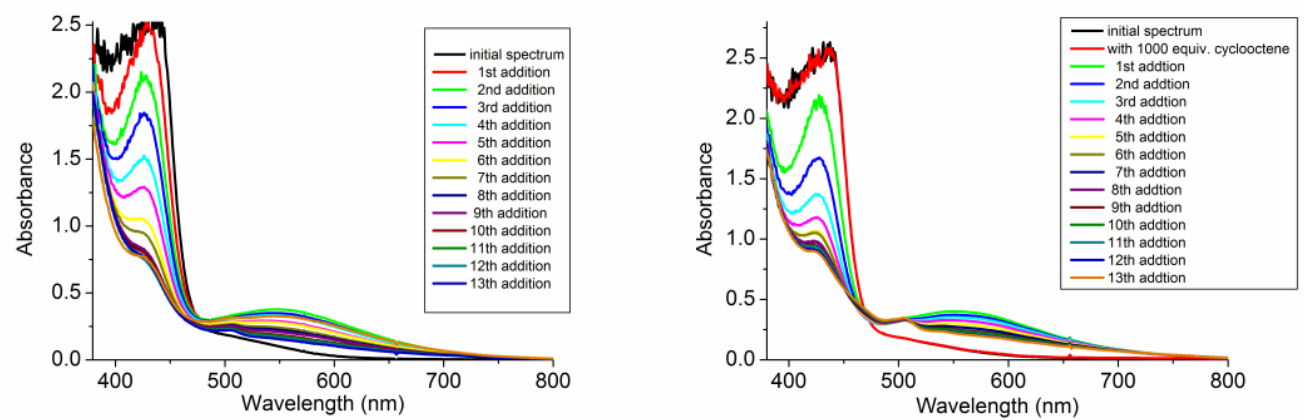

Figure S 14. Absorption spectra recorded where absorbance at $551 \mathrm{~nm}$ has reached a maximum following each addition (ca. 4 equiv. each) of a total of 50 equiv. of $\mathrm{H}_{2} \mathrm{O}_{2}$ to 1 $(0.875 \mathrm{mM})$ in acetonitrile (left) without and (right) with cyclooctene $(0.875 \mathrm{M})$. See Figure 9 in the main text. 


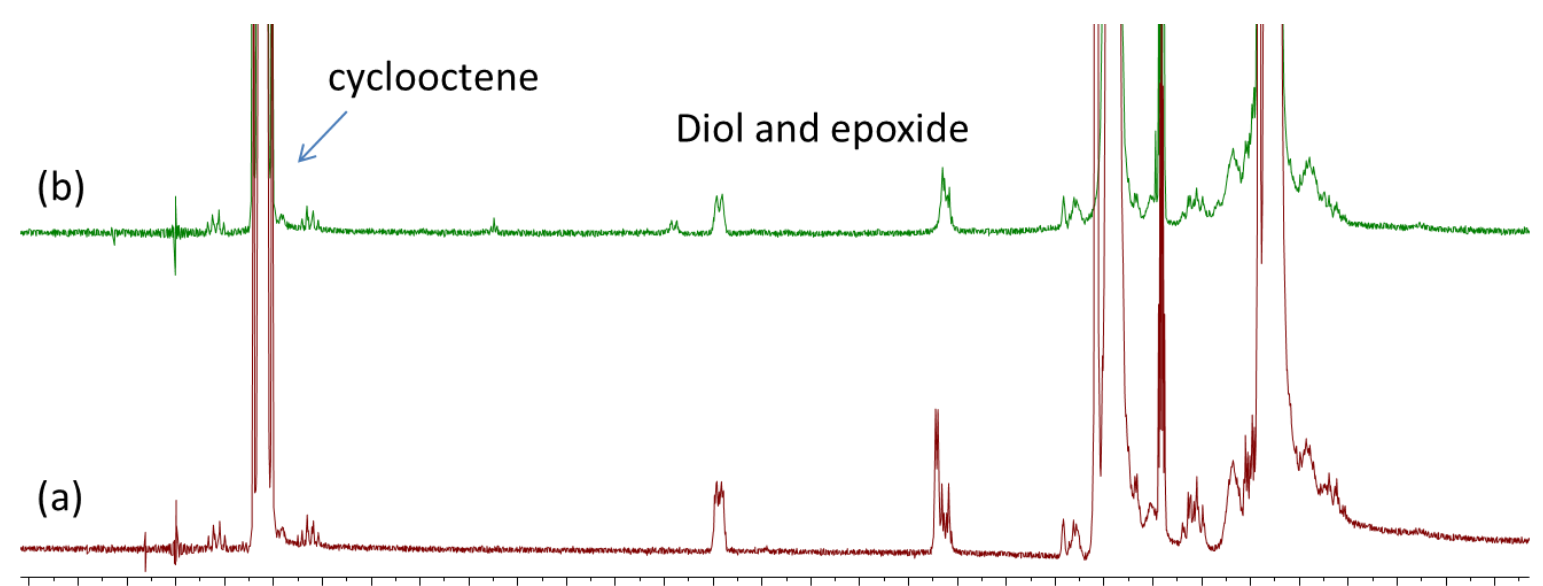

$\begin{array}{lllllllllllllllllllllllllllllllllllllllll}6.6 & 6.4 & 6.2 & 6.0 & 5.8 & 5.6 & 5.4 & 5.2 & 5.0 & 4.8 & 4.6 & 4.4 & 4.2 & 4.0 & 3.8 & 3.6 & 3.4 & 3.2 & 3.0 & 2.8 & 2.6 & 2.4 & 2.2 & 2.0 & 1.8 & 1.6 & 1.4 & 1.2 & 1.0 & 0.8 & 0.6\end{array}$

ppm

Figure S 15. ${ }^{1} \mathrm{H}$ NMR spectra of the product mixtures of oxidation of cyclooctene to epoxide and diol products by 1 with $\mathrm{H}_{2} \mathrm{O}_{2}$. (a) Cyclooctene oxide (12.3 equiv., $4.7 \mathrm{mg}$ ) and cis-1,2cyclooctane diol (22 equiv., $8.3 \mathrm{mg}$ ) were added to $3 \mathrm{ml}$ of $\mathrm{CD}_{3} \mathrm{CN}$ with cyclooctene $(0.875$ M, 1000 equiv.) followed by $14 \mathrm{ul}$ of $\mathrm{H}_{2} \mathrm{O}$ was added. An aliquot of the mixture was passed over anhydrous $\mathrm{MgSO}_{4}$ and its ${ }^{1} \mathrm{H}$ NMR spectrum was recorded (note that the spectra before and after passing over $\mathrm{MgSO}_{4}$ was the same). (b) Cyclooctene (0.875 M, 1000 equiv.) was added to 1 ( $0.875 \mathrm{mM}, 1$ equiv.) in $\mathrm{CD}_{3} \mathrm{CN}$ followed by addition of 50 eq. $\mathrm{H}_{2} \mathrm{O}_{2}$ over $1 \mathrm{~h}$ with stirring and monitoring by UV/Vis absorption spectroscopy (see Figure 9 and Figure S12). After $1 \mathrm{~h}$, an aliquot of the solution was passed over anhydrous $\mathrm{MgSO}_{4}$ and its ${ }^{1} \mathrm{H}$ NMR was recorded. 
(a)

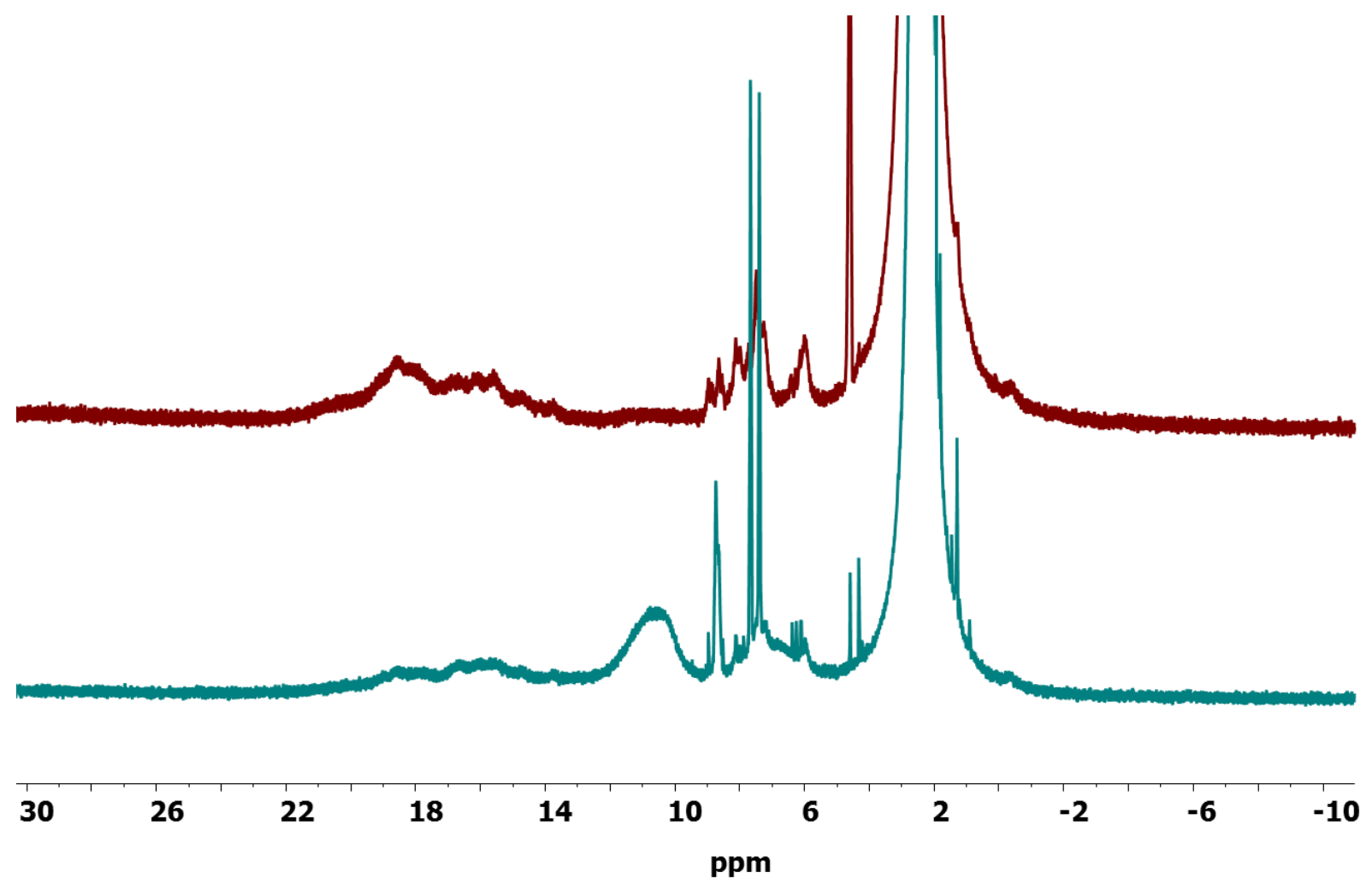

(b)

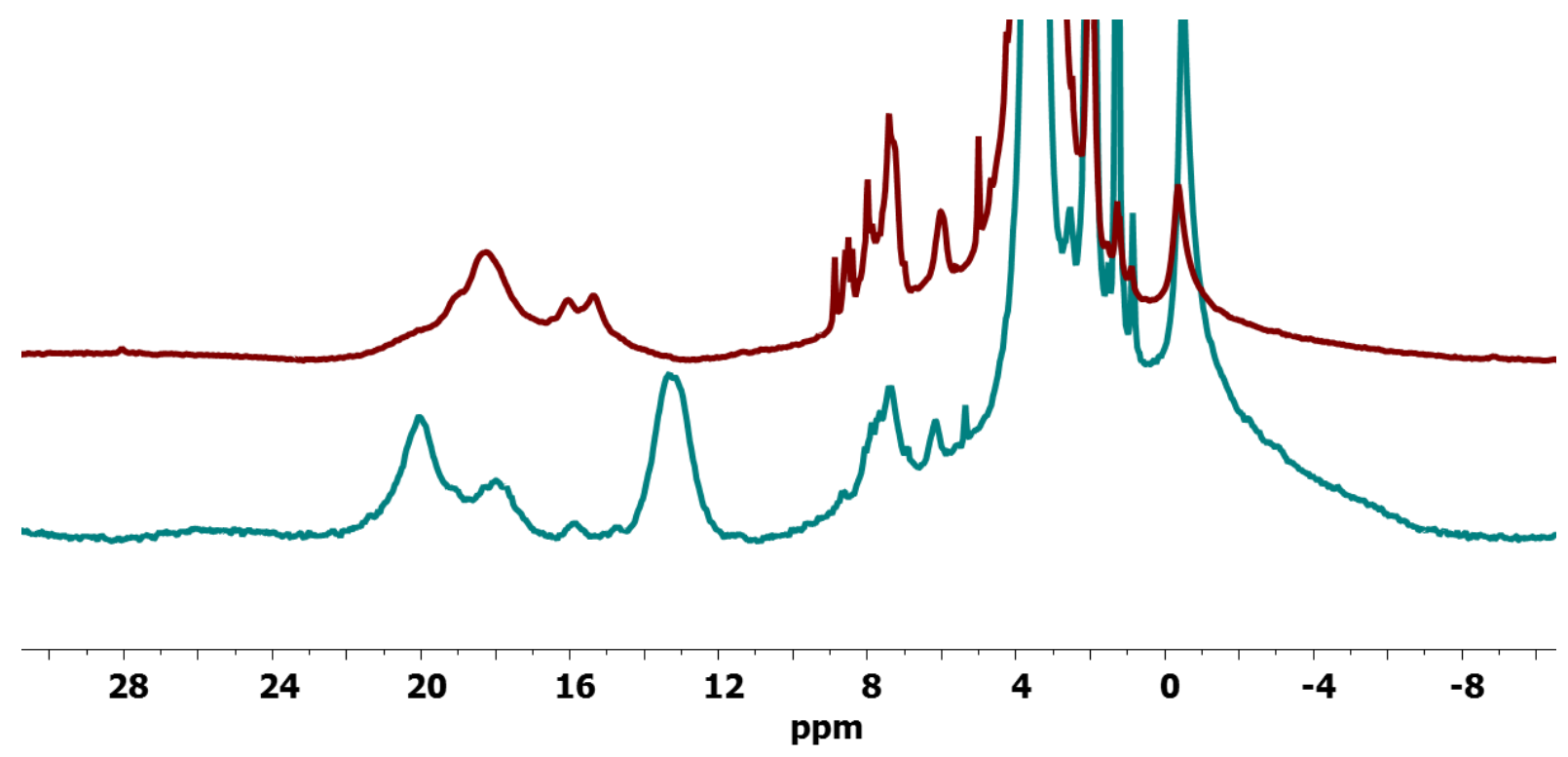

Figure S 16. ${ }^{1} \mathrm{H}$ NMR (400 MHz) spectra of $\mathbf{1}$ (a) $1 \mathrm{mM}$, and (b) spectra $10 \mathrm{mM}$ in $\mathrm{CD}_{3} \mathrm{CN}$ after addition of water $\left(1 \mathrm{M}\right.$, blue), and further subsequent addition of 18 and 25 equiv. $\mathrm{H}_{2} \mathrm{O}_{2}$ (brown), respectively. 


\section{ESI-MS data}

The ESI-MS of 1 in $\mathrm{CH}_{3} \mathrm{CN}$ shows ions at m/z 193.7 and 214.3 with the expected isotopic distribution for $\left[\mathrm{LFe}(\mathrm{II})\left(\mathrm{CH}_{3} \mathrm{CN}\right)\right]^{2+}$ (where $\left.\mathrm{L}=\mathrm{MeN} 3 \mathrm{Py}\right)$ and $\left[\mathrm{LFe}(\mathrm{II})\left(\mathrm{CH}_{3} \mathrm{CN}\right)_{2}\right]^{2+}$, respectively. Addition of water $(1.3 \mathrm{M})$ results in disappearance of the original signals with a single signal remaining at $\mathrm{m} / \mathrm{z} 372.3$, with an isotope pattern consistent with a monocationic iron complex.

In contrast, addition of 25 or 100 equiv . of $\mathrm{H}_{2} \mathrm{O}_{2}$ has relatively little effect on the spectrum compared to that of 1 in $\mathrm{CH}_{3} \mathrm{CN}$ alone except for two weak additional signals at $\mathrm{m} / \mathrm{z} 251.3$ and 255.9, which correspond to $[\mathrm{LFe}(\mathrm{III})(\mathrm{O})(\mathrm{HCOO}) \mathrm{Fe}(\mathrm{III}) \mathrm{L}]^{3+}$ and $\left[\mathrm{LFe}(\mathrm{III})(\mathrm{O})\left(\mathrm{CH}_{3} \mathrm{COO}\right) \mathrm{Fe}(\mathrm{III}) \mathrm{L}\right]^{3+}$, respectively.

Addition of 100 equiv. of water and 100 equiv. of $\mathrm{H}_{2} \mathrm{O}_{2}$ to 1 in $\mathrm{CH}_{3} \mathrm{CN}$ resulted in the appearance of additional signals at $\mathrm{m} / \mathrm{z} 372.3,391.3$ and 445.3, with the latter corresponding to $\left[\mathrm{LFe}\left(\mathrm{ClO}_{4}\right)\right]^{+}$.

Addition of 100 equiv. of acetic acid to 1 in $\mathrm{CH}_{3} \mathrm{CN}$ results in a signal at $\mathrm{m} / \mathrm{z}$ 464.3, which correspond to $\left[\mathrm{LFe}(\mathrm{III})\left(\mathrm{CH}_{3} \mathrm{COO}\right)_{2}\right]^{+}$(with an increase of $3 \mathrm{~m} / \mathrm{z}$ units with $\mathrm{CD}_{3} \mathrm{CO}_{2} \mathrm{D}$ ) and the addition of 100 equiv of $\mathrm{H}_{2} \mathrm{O}_{2}$ has little if any effect on the spectrum. A weak signals at $\mathrm{m} / \mathrm{z}$ 413 can be assigned to [LFe(III) $\left.\left(\mathrm{CH}_{3} \mathrm{COO}\right)_{2}(\mathrm{O}) \mathrm{Fe}(\mathrm{III}) \mathrm{L}\right]^{2+}$, which is shifted to 416 with $\mathrm{CD}_{3} \mathrm{COD}$ and at 422 to $\left[\mathrm{LFe}(\mathrm{III})\left(\mathrm{CH}_{3} \mathrm{COO}\right)(\mathrm{OH})\right]^{+}$, which shifts to 425 with $\mathrm{CD}_{3} \mathrm{COD}$. 


\section{ESI-MS spectrum of 1 in $\mathrm{CH}_{3} \mathrm{CN}$}

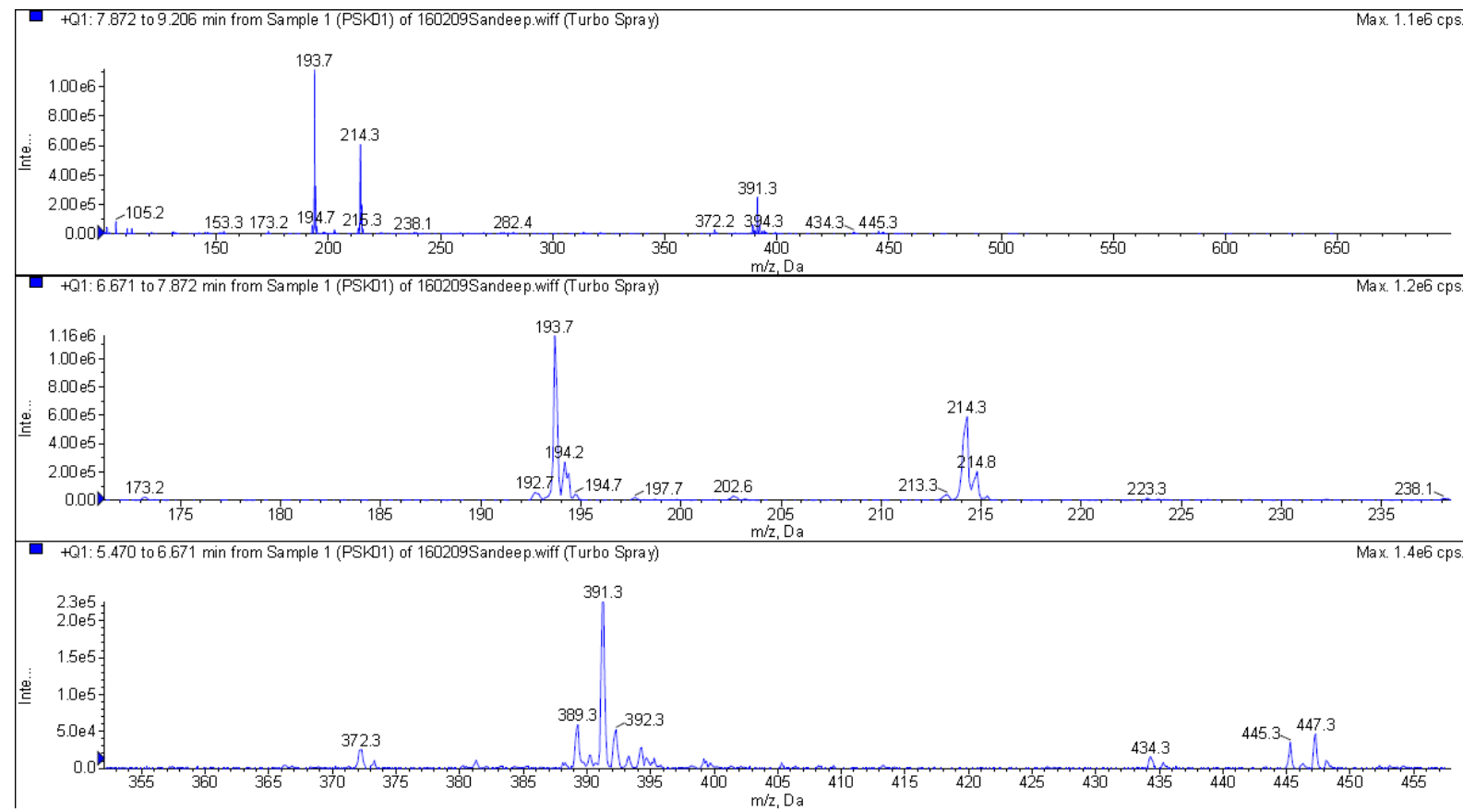




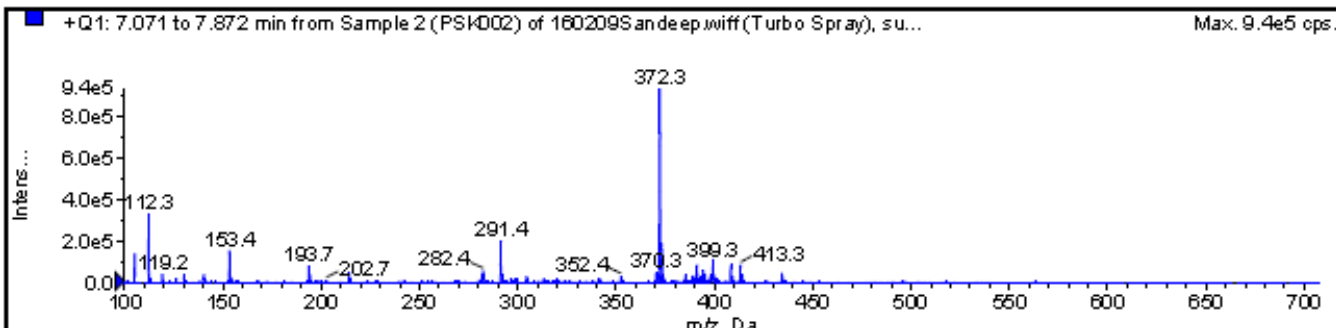

+Q1: 6.404 to 7.738 min from Sample 2 (PSKOC2) of $160209 \mathrm{~S}$ ande ep swiff( (Turbo Spray)

$3.6 \mathrm{e} 5$
$3.0 \mathrm{e} 5$
$2.0 \mathrm{e} 5$
$1.0 \mathrm{e} 5$

112.3

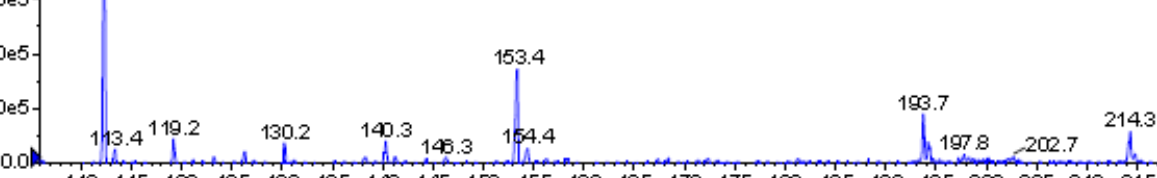

$\begin{array}{llllllllllllllllllllllllllllll}110 & 115 & 120 & 125 & 130 & 135 & 140 & 145 & 150 & 155 & 160 & 165 & 170 & 175 & 180 & 185 & 190 & 195 & 200 & 205 & 210 & 215 & 220\end{array}$

+Q1: 5.337 to 6.404 min from Sample 2 (PSW002) of $160209 \mathrm{~S}$ ande ep uniff (Turbo Spray)

Max. $9.0 \mathrm{e} 5 \mathrm{cps}$

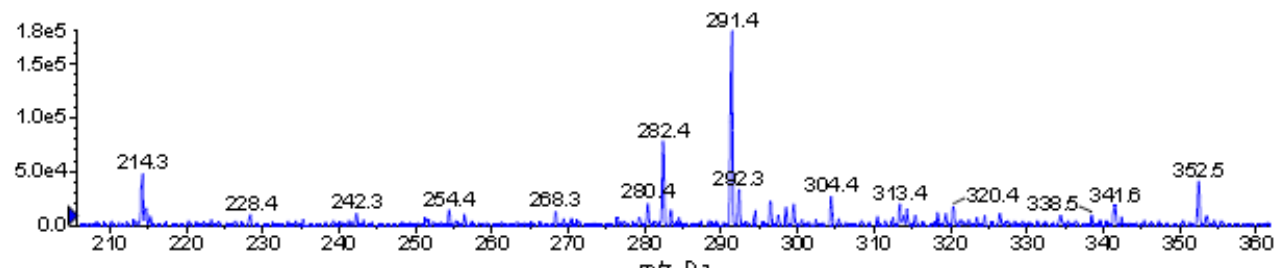

+Q1: 5.604 to 7.071 min from Sample 2 (PSK002) of 160209 S ande ep uniff (Turbo Spray), su..

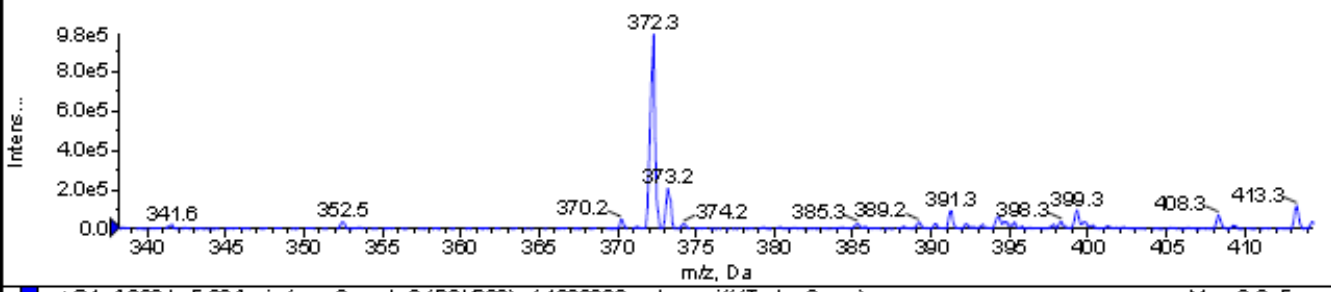

+Q1: 4.269 to 5.604 min from Sample 2 (PSWO02) of 160209 S ande ep mifft (Turbo Spr ay), su...

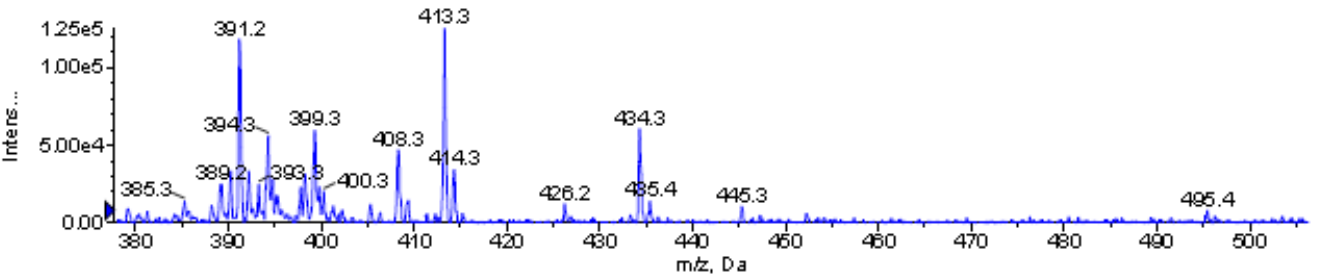


ESI-MS spectrum of 1 in $\mathrm{CH}_{3} \mathrm{CN}$ with 25 equiv. $\mathrm{H}_{2} \mathrm{O}_{2}$

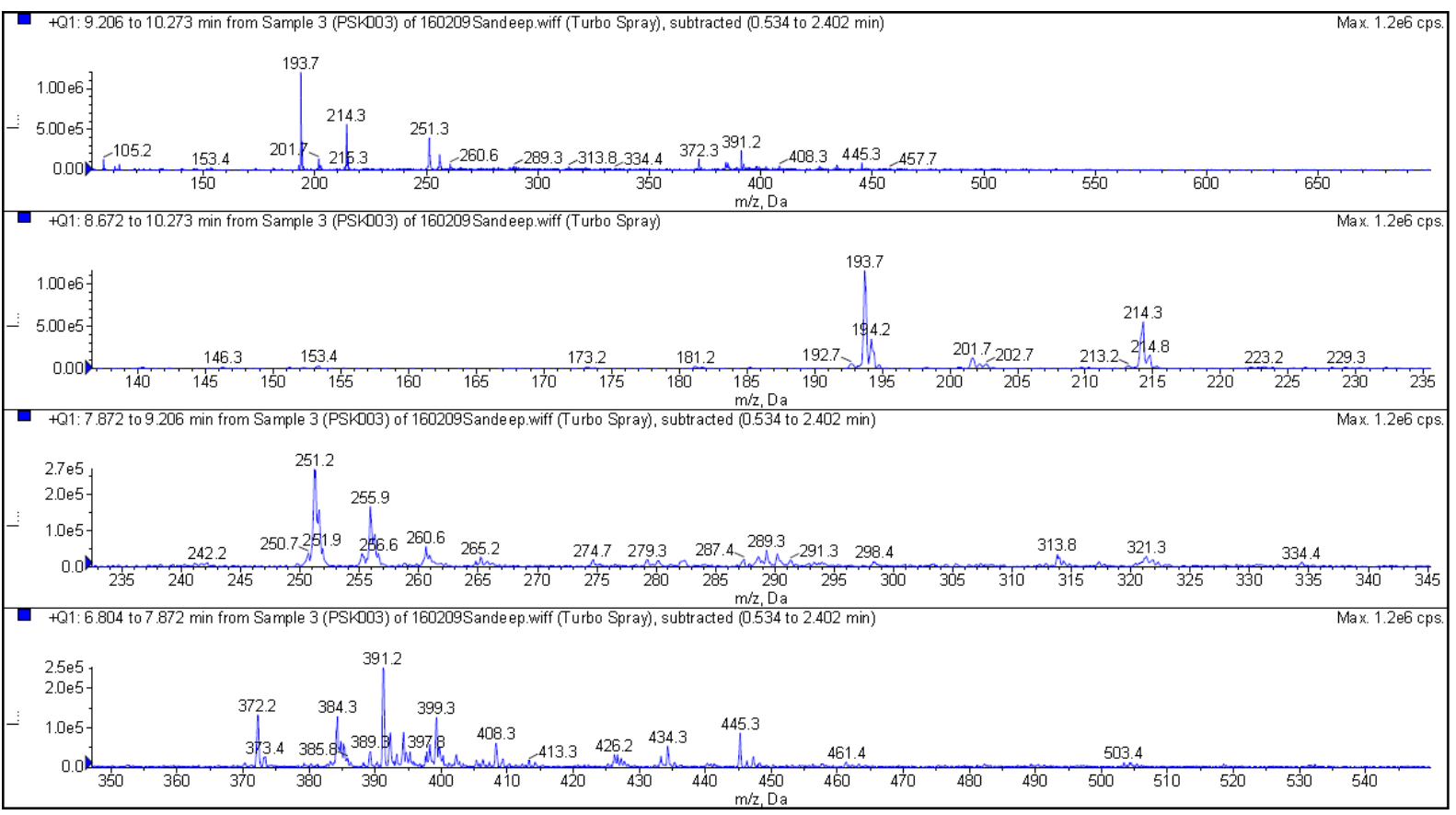

\section{ESI-MS spectrum of 1 in $\mathrm{CH}_{3} \mathrm{CN}$ with 100 equiv. $\mathrm{H}_{2} \mathrm{O}_{2}$}

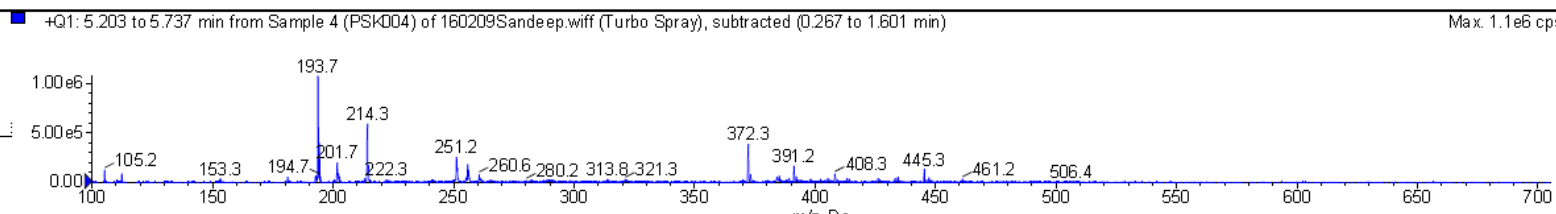

- +Q1: 4.536 to 5.203 min from Sample 4 (PSKD04) of 160209Sande ep. wiff (Turbo Spray), subtracted (0.267 to $1.601 \mathrm{~min}$ )

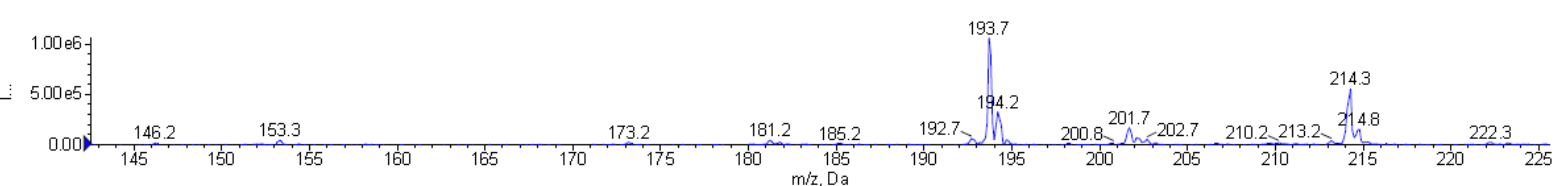

- +Q1:3.602 to 4.536 min from Sample 4 (PSK004) of 160209Sandeep.wiff (Turbo Spray), subtracted (0.267 to $1.601 \mathrm{~min}$ )

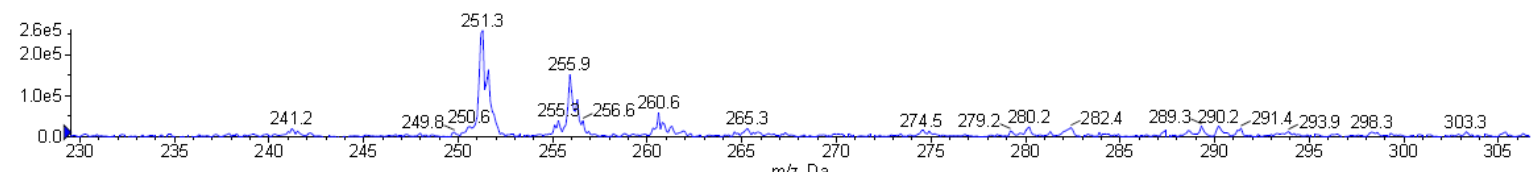

- +Q1: 2.668 to 3.602 min from Sample 4 (PSKD04) of 160209Sandeep.wiff (Turbo Spray), subtracted (0.267 to $1.601 \mathrm{~min})$

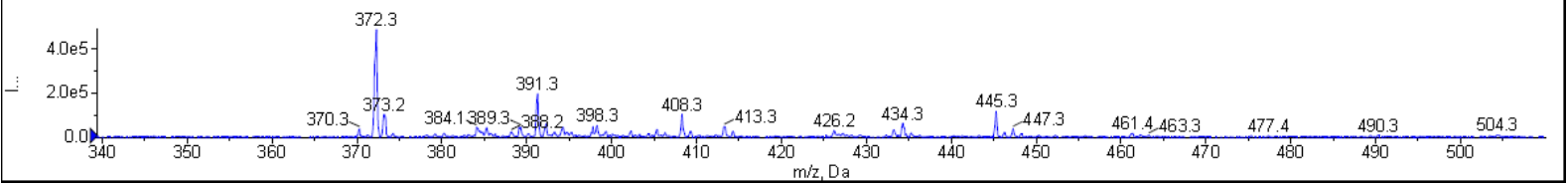


ESI-MS spectrum of 1 in $\mathrm{CH}_{3} \mathrm{CN}$ with 100 equiv. $\mathrm{H}_{2} \mathrm{O}$ and 100 equiv. $\mathrm{H}_{2} \mathrm{O}_{2}$

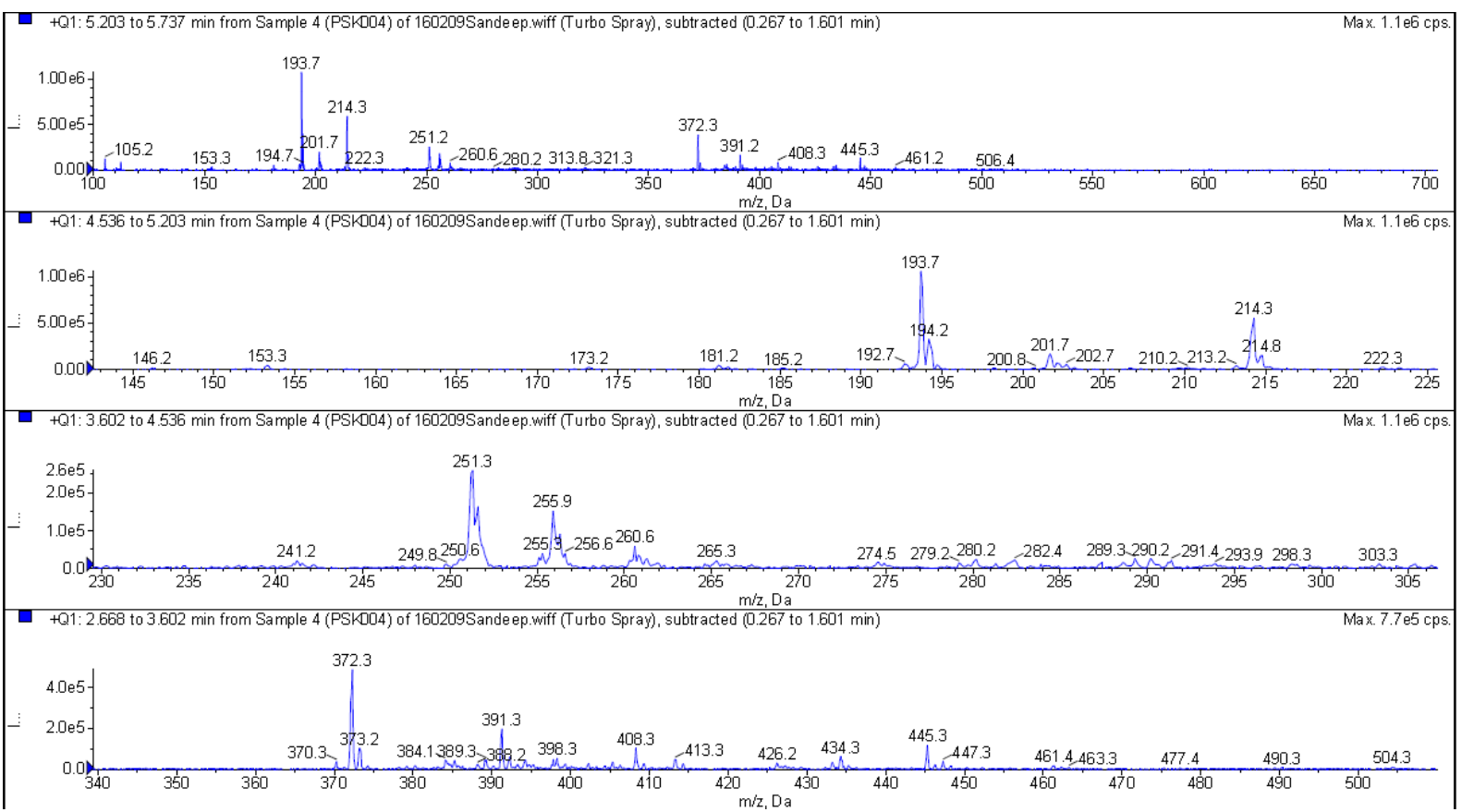

ESI-MS spectrum of 1 in $\mathrm{CH}_{3} \mathrm{CN}$ with 100 equiv. (a) acetic acid and (b) $\mathrm{d}_{4}$-acetic acid

(a)

+Q1: 5.337 to 6.137 min from Sample 8 (PSK006 with AcN+HAc) of 160209Sandeep.wiff (T...

Max. $8.5 \mathrm{e} 5 \mathrm{cps}$

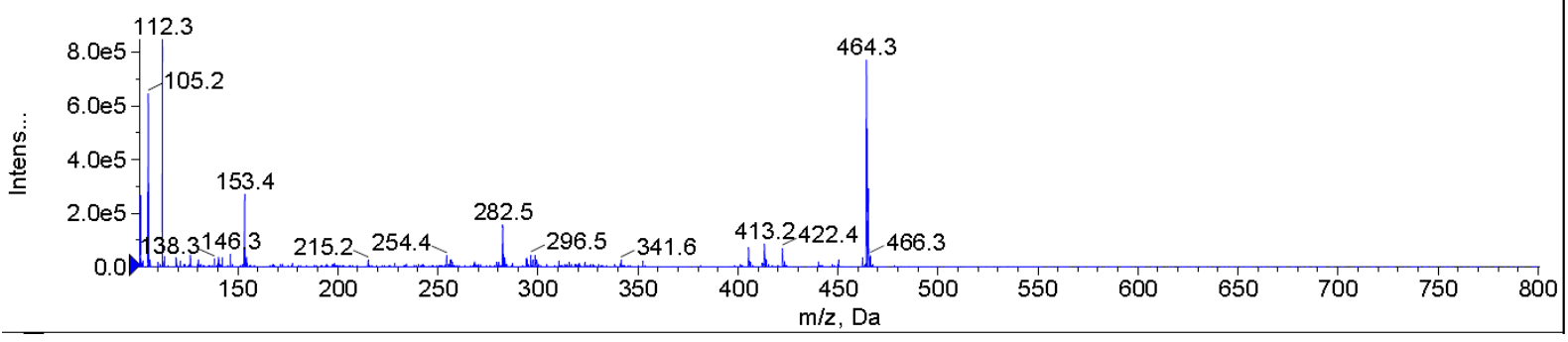

(b)

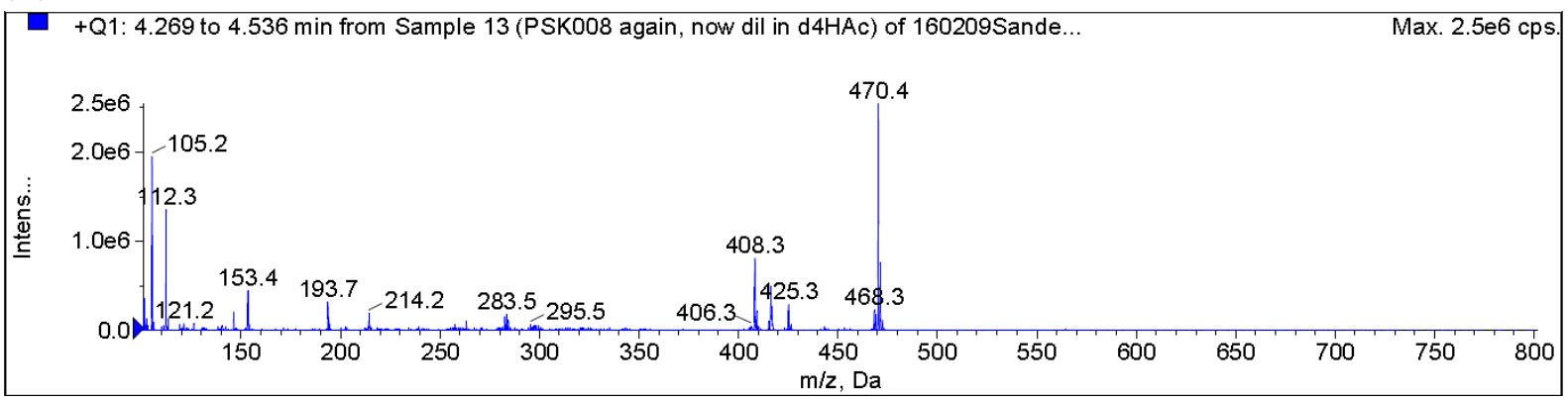


ESI-MS spectrum of 1 in $\mathrm{CH}_{3} \mathrm{CN}$ with 100 equiv. of $\mathrm{H}_{2} \mathrm{O}_{2}$ and 100 equiv. (a) acetic acid and (b) $\mathrm{d}_{4}$-acetic acid

(a)

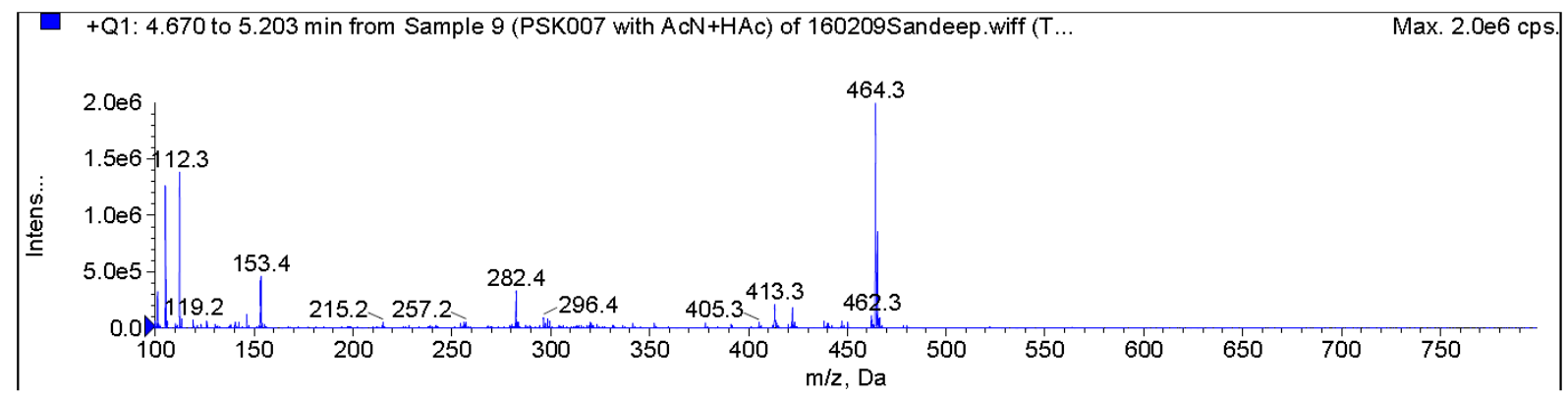

(b)

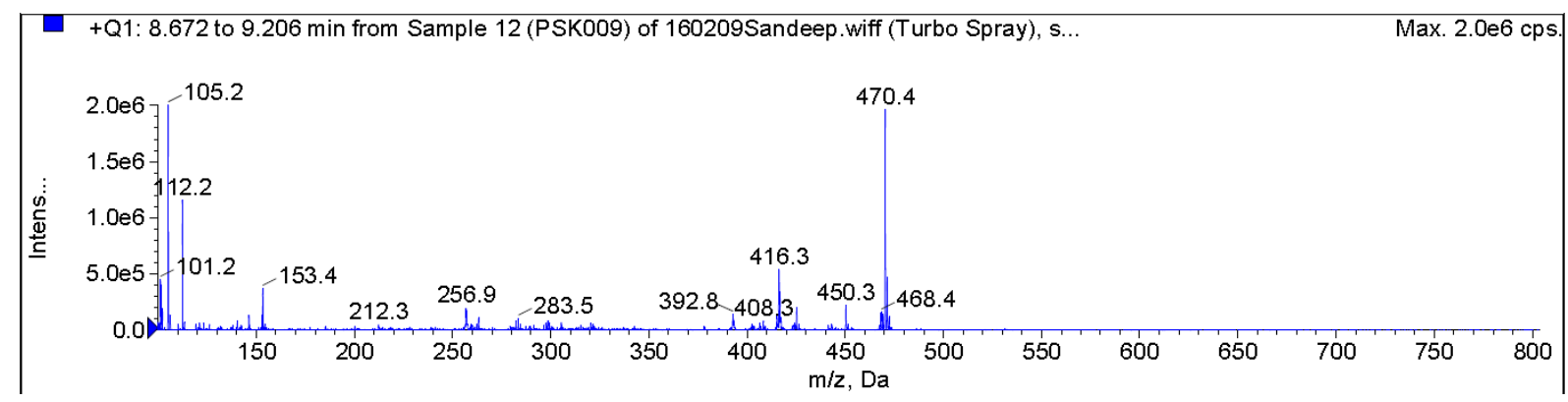

